\title{
Carnosine Facilitates Nitric Oxide Production in Endothelial F-2 Cells
}

\author{
Satoru TAKAHASHI, ${ }^{* a}$ Yukiko NAKASHIMA, ${ }^{a}$ and Ken-ichi TodA ${ }^{b}$ \\ ${ }^{a}$ First Department of Biochemistry, School of Pharmaceutical Sciences, Kyushu University of Health and Welfare; 1714-1 \\ Yoshino, Nobeoka, Miyazaki 882-0072, Japan: and ${ }^{b}$ Department of Dermatology, The Tazuke Kofukai Medical Institute, \\ Kitano Hospital; 2-4-20 Ohgimachi, Kita-ku, Osaka 530-8480, Japan. \\ Received June 8, 2009; accepted September 3, 2009; published online September 4, 2009
}

We examined the effect of carnosine ( $\beta$-alanyl-histidine) on nitric oxide (NO) production and endothelial NO synthase (eNOS) activation in endothelial F-2 cells. Carnosine enhanced NO production in a dose-dependent manner, and the stimulatory effect of carnosine was observed at concentrations exceeding 5 mm. The carnosinestimulated NO production was inhibited by $N^{\mathrm{G}}$-nitro-L-arginine methyl ester, but not by $N^{\mathrm{G}}$-nitro-D-arginine methyl ester. In contrast, $\beta$-alanine, histidine (carnosine components) and anserine $(N$-methyl carnosine) failed to increase NO production. Carnosine had no effect on NO production for the initial 5 min, but thereafter resulted in a gradual increase in NO production up to $15 \mathrm{~min}$. Carnosine did not induce phosphorylation of eNOS at Ser1177. The carnosine-induced increase in NO production was observed even when extracellular $\mathrm{Ca}^{2+}$ was depleted by ethylene glycol bis(2-aminoethyl ether)- $N, N, N^{\prime}-N^{\prime}$-tetraacetic acid however, the effect was abolished upon depletion of intracellular $\mathrm{Ca}^{2+}$ by BAPTA. After F-2 cells were incubated with carnosine for 4 min, intracellular $\mathrm{Ca}^{2+}$ concentration gradually increased. The carnosine-induced increase in intracellular $\mathrm{Ca}^{2+}$ concentration occurred even in the absence of extracellular $\mathrm{Ca}^{2+}$. These results indicate that carnosine facilitates NO production in endothelial F-2 cells. It is also suggested that eNOS is activated by $\mathrm{Ca}^{2+}$, which might be released from intracellular $\mathrm{Ca}^{2+}$ stores in response to carnosine.

Key words carnosine; endothelial cell; nitric oxide; endothelial nitric oxide synthase; intracellular $\mathrm{Ca}^{2+}$

Carnosine is a dipeptide composed of $\beta$-alanine and histidine. It is synthesized endogenously, ${ }^{1)}$ and it is also ingested as a part of diets comprising meat, fish and chicken and is absorbed intact from the gastrointestinal tract. ${ }^{2,3)}$ Carnosine is found in millimolar concentrations in various tissues, and is especially abundant in the heart, muscles and brain., ${ }^{4,5)}$ The exact physiological role of carnosine remains unclear, but various effects of carnosine have been reported. Further, carnosine is expected to have therapeutic potential. ${ }^{6}$ However, the effect of carnosine on endothelial function has not been investigated, although the endothelium is exposed to the dipeptide after ingestion. In addition, the effect of carnosine on vascular tone has been a matter of debate. Ririe et al. ${ }^{7)}$ showed that carnosine causes relaxation of the isolated rat aorta, whereas O'Dowd et al.$^{8)}$ reported that the dipeptide induces sustained constriction of the isolated rabbit saphenous vein.

Endothelial cells constitutively produce nitric oxide (NO), which plays an important role in regulating vascular tone, platelet aggregation and endothelial viability., ${ }^{9}$ ) Endothelial NO synthase (eNOS) is responsible for the physiological production of NO in endothelial cells.

We therefore examined whether carnosine affects NO production and eNOS activation in cultured endothelial cells.

\section{MATERIALS AND METHODS}

Materials Unless otherwise indicated, all the reagents used in this study and their sources are as follows: L-carnosine, L-anserine nitrate, $\beta$-alanine, L-histidine, $N^{\mathrm{G}}$-nitro-Larginine methyl ester (L-NAME), $N^{\mathrm{G}}$-nitro-D-arginine methyl ester (D-NAME) and bradykinin (Sigma-Aldrich Co., St. Louis, MO, U.S.A.); protease inhibitor mixture set III and 1,2-bis(2-aminophenoxy)ethane- $N, N, N^{\prime}, N^{\prime}$-tetraacetic acid (BAPTA-AM) (Calbiochem, La Jolla, CA, U.S.A.); anti-
eNOS antibody (BD Transduction Laboratories, Lexington, KY, U.S.A.); anti-peNOS antibody (phospho-Ser1177), secondary antibody linked to peroxidase and Phototope-HRP Western blot detection system (Cell Signaling, Beverly, MA, U.S.A.); Immobilon P membrane (Millipore, Bedford, MA, U.S.A.); Calcium kit-Fluo 3 (Dojin, Kumamoto, Japan); cell culture media and supplies (Invitrogen, Carlsbad, CA, U.S.A.). All other chemicals were of reagent grade.

Cell Culture F-2 cells, murine vascular endothelial cell line, ${ }^{11)}$ were maintained in Dulbecco's modified Eagle's medium supplemented with $10 \%$ fetal bovine serum, $100 \mathrm{U} / \mathrm{ml}$ penicillin, and $100 \mu \mathrm{g} / \mathrm{ml}$ streptomycin in the final concentration at $37^{\circ} \mathrm{C}$ in $5 \% \mathrm{CO}_{2}$ and $95 \%$ air.

Determination of NO Production F-2 cells were seeded in 12-well plates and were allowed to grow to confluence. The cells were starved over night in serum-free medium containing $1 \mathrm{mg} / \mathrm{ml}$ bovine serum albumin, and then conditioned in phosphate-buffered saline (PBS) containing $10 \mathrm{~mm}$ HEPES-NaOH (pH 7.4), and $1 \mathrm{mg} / \mathrm{ml}$ bovine serum albumin for $1 \mathrm{~h}$ before the experiments. The cells were pretreated with vehicle or $5 \mathrm{~mm}$ L-NAME for $10 \mathrm{~min}$ and then stimulated with $1 \mu \mathrm{M}$ bradykinin, $10 \mathrm{~mm}$ carnosine, $10 \mathrm{~mm}$ anserine, $10 \mathrm{~mm} \beta$-alanine or $10 \mathrm{~mm}$ histidine, unless otherwise indicated. At appropriate times, the medium was sampled. NO was determined as nitrite by colorimetry after the Griess reaction. ${ }^{12,13)}$ The released NO into the medium was completely oxidized to nitrite when left standing over night at $4{ }^{\circ} \mathrm{C}$. In a preliminary study, the amount of nitrite was confirmed to be stable under this condition. The amount of nitrite was measured using a NOx analyzer (ENO-200; EICOM, Kyoto, Japan).

The depletion of extracellular or intracellular $\mathrm{Ca}^{2+}$ was achieved by incubating the cells in $\mathrm{Ca}^{2+}$-free PBS containing $10 \mathrm{~mm}$ HEPES-NaOH (pH 7.4), $1 \mathrm{~mm}$ EGTA and $1 \mathrm{mg} / \mathrm{ml}$ bovine serum albumin with or without $50 \mu \mathrm{M}$ BAPTA-AM 
for 30 min. Thereafter, the medium was replaced with $\mathrm{Ca}^{2+}$ free PBS containing $10 \mathrm{~mm}$ HEPES-NaOH ( $\mathrm{pH} 7.4$ ), $0.1 \mathrm{~mm}$ EGTA, $1 \mathrm{mg} / \mathrm{ml}$ bovine serum albumin.

Immunoblotting of eNOS eNOS was detected as described previously. ${ }^{14)} \mathrm{F}-2$ cells were seeded in 35-mm dishes and were allowed to grow to confluence. After incubation with $1 \mu \mathrm{M}$ bradykinin or $10 \mathrm{~mm}$ carnosine for $10 \mathrm{~min}$, the F-2 cells were lysed in $20 \mathrm{~mm}$ Tris- $\mathrm{HCl}$ (pH 7.5), $1 \mathrm{~mm}$ EDTA, $100 \mathrm{~mm} \mathrm{NaCl}, 10 \mathrm{~mm}$ sodium orthovanadate, $10 \mathrm{~mm}$ sodium fluoride, $10 \mathrm{~mm} \beta$-glycerophosphate, $1 \%$ Triton $\mathrm{X}-100,0.5 \%$ sodium deoxycholate and the protease inhibitor mixture. The lysates were placed on ice for $10 \mathrm{~min}$ and were then centrifuged at $10000 \mathrm{rpm}$ for $10 \mathrm{~min}$ at $4{ }^{\circ} \mathrm{C}$. The supernatants were subjected to SDS-polyacrylamide gel electrophoresis (SDS-PAGE) and then blotted onto Immobilon P membranes. The blots were incubated over night with the primary antibody at $4{ }^{\circ} \mathrm{C}$ and then probed with the secondary antibody linked to peroxidase. Immunoreactive proteins were visualized using an enhanced chemiluminescence kit.

Determination of Intracellular $\mathrm{Ca}^{2+}$ Concentration Intracellular $\mathrm{Ca}^{2+}$ concentration was measured in the cells loaded with Fluo 3. ${ }^{15)} \mathrm{F}-2$ cells were incubated with $5 \mathrm{mg} / \mathrm{ml}$ Fluo 3-AM for $90 \mathrm{~min}$. The cells were washed with PBS and then held for $15 \mathrm{~min}$. Relative fluorescence intensity was monitored at an excitation and emission wavelength of $485 \mathrm{~nm}$ and $535 \mathrm{~nm}$, respectively.

Statistical Analysis Data are presented as means \pm S.E. Statistical differences in the dose-response study were evaluated by applying Dunnett's multiple comparison test. Student's $t$-test was used for comparing two groups. A $p$ value of $<0.05$ was regarded as significant.

\section{RESULTS}

Carnosine-Induced Increase in NO Production in Endothelial Cells Endothelial F-2 cells produced NO under the control condition without any stimulus (Fig. 1A). When F-2 cells were incubated with carnosine for $10 \mathrm{~min}$, carnosine enhanced NO production in a dose-dependent manner. The stimulatory effect of carnosine was observed at concentrations above $5 \mathrm{~mm}$, and reached a plateau level at $10 \mathrm{~mm}$. Carnsine at $10 \mathrm{~mm}$ significantly stimulated NO production, although the effect of carnosine was lower than that of $1 \mu \mathrm{M}$ bradykinin (Fig. 1B). Pretreatment with $5 \mathrm{~mm}$ L-NAME potently reduced both basal, carnosine- and bradykinin-stimulated NO production. In contrast, $5 \mathrm{~mm}$ D-NAME did not affect basal or stimulated NO production. These results indicate that the observed NO production is mediated by eNOS.

We examined whether $\beta$-alanine, histidine (carnosine components) and anserine ( $N^{1}$-methyl-carnosine) also stimulate NO production in F-2 cells (Fig. 2). However, none of the compounds at $10 \mathrm{~mm}$ had any effect on NO production for $10 \mathrm{~min}$. Further, the combination of $10 \mathrm{~mm} \beta$-alanine and $10 \mathrm{~mm}$ histidine failed to increase $\mathrm{NO}$ production.

Carnosine at $10 \mathrm{~mm}$ had no effect on NO production up to $5 \mathrm{~min}$, and thereafter gradually increased $\mathrm{NO}$ production in a time-dependent manner (Fig. 3). The carnosine-stimulated NO production for 10 and $15 \mathrm{~min}$ was 171.1 and $201.3 \%$, respectively, and was significantly higher than the control. However, the effect of carnosine disappeared between 15 $30 \mathrm{~min}$, and the NO accumulation rate at this stage was al-
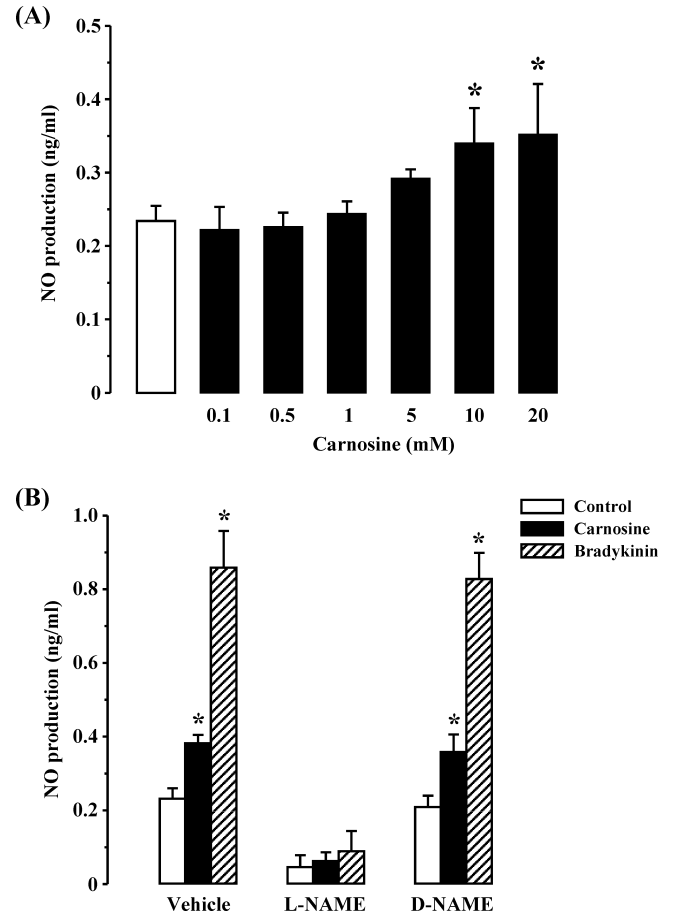

Fig. 1. Effect of Carnosine on NO Production in Endothelial Cells

(A) F-2 cells were incubated with vehicle (control) or $0.1-20 \mathrm{~mm}$ carnosine for $10 \mathrm{~min}$. The released NO into the medium was determined. (B) After F-2 cells were pretreated with vehicle, $5 \mathrm{~mm}$ L-NAME or $5 \mathrm{~mm}$ D-NAME, the cells were stimulated with vehicle (control), $10 \mathrm{~mm}$ carnosine or $1 \mu \mathrm{m}$ bradykinin for $10 \mathrm{~min}$. The released NO into the medium was determined. The data are mean \pm S.E. for five experiments. * Significantly different from the control.

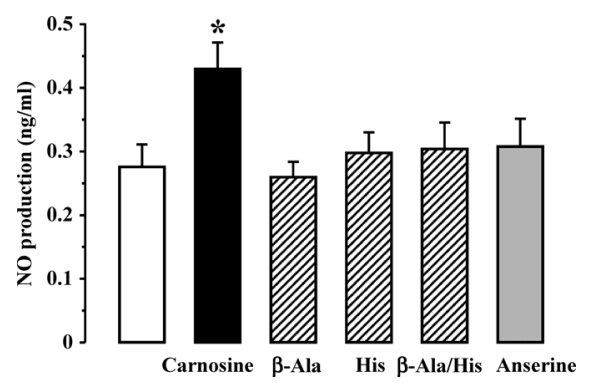

Fig. 2. Effect of Carnosine-Related Compounds on NO Production in Endothelial Cells

F-2 cells were incubated with vehicle (control) or the indicated compound at $10 \mathrm{~mm}$ for $15 \mathrm{~min}$. The released NO into the medium was determined. The data are mean \pm S.E. for five experiments. * Significantly different from the control.

most the same as that of the control. In contrast, bradykinin at $1 \mu \mathrm{M}$ rapidly and markedly enhanced NO production, as detemined from the high rate of $\mathrm{NO}$ accumulation $0-2$ min after the start of the reaction as compared with the later stage. NO production stimulated by bradykinin was $390.6 \%$ for $2 \mathrm{~min}$ and $528.9 \%$ for $10 \mathrm{~min}$, compared with the control.

Mechanism Underlying the Carnosine-Induced Increase in NO Production eNOS activity primarily depends on intracellular $\mathrm{Ca}^{2+}$ levels and is further regulated by protein kinases such as Akt. ${ }^{14,16-18)}$ It was examined whether the increased NO production caused by carnosine is mediated by the phosphorylation of eNOS at Ser-1177 (Fig. 4). When F-2 cells were incubated with $10 \mathrm{~mm}$ carnosine for $10 \mathrm{~min}$, eNOS phosphorylation was not promoted. In contrast, $1 \mu \mathrm{M}$ bradykinin clearly facilitated the phosphorylation of eNOS. 


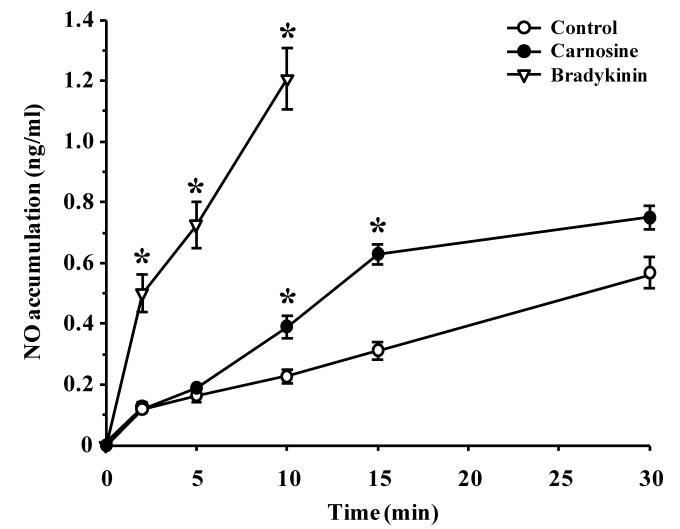

Fig. 3. Time Course of Carnosine-Induced Increase in NO Production in Endothelial Cells

F-2 cells were incubated with vehicle (control), $10 \mathrm{~mm}$ carnosine or $1 \mu \mathrm{M}$ bradykinin for the indicated times. The released NO into the medium was determined. The data are mean \pm S.E. for five experiments. * Significantly different from the control.

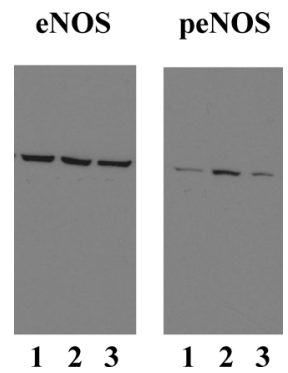

Fig. 4. Effect of Carnosine on Phosphorylation of eNOS in Endothelial Cells

F-2 cells were incubated with vehicle (control), $1 \mu \mathrm{M}$ bradykinin or $10 \mathrm{~mm}$ carnosine for $10 \mathrm{~min}$. The phosphorylation of eNOS at Ser1177 was examined by immunoblotting. The data are representative of three experiments. Lane 1, control; lane 2, bradykinin; and lane 3, carnosine

We next examined the $\mathrm{Ca}^{2+}$ requirement for the stimulatory effect of carnosine (Fig. 5). The depletion of extracellular and intracellular $\mathrm{Ca}^{2+}$ was achieved by treating the cells with EGTA and BAPTA-AM in $\mathrm{Ca}^{2+}$-free PBS, respectively. Up to $10 \mathrm{~min}$, the basal NO production in the presence of EGTA or BAPTA-AM was reduced to approximately $60 \%$ of that observed under normal $\mathrm{Ca}^{2+}$ levels. NO production continued to remain significantly increased in response to $10 \mathrm{~mm}$ carnosine or $1 \mu \mathrm{M}$ bradykinin even though extracellular $\mathrm{Ca}^{2+}$ was depleted. In contrast, the depletion of intracellular $\mathrm{Ca}^{2+}$ abolished the effect of carnosine. Carnosine-induced NO production was slightly enhanced, and the increase was only $19.6 \%$ greater than that of the control. In addition, the effect of bradykinin on $\mathrm{NO}$ production was potently inhibited by BAPTA-AM.

When intracellular $\mathrm{Ca}^{2+}$ concentration was measured in Fluo 3-loaded F-2 cells, the $\mathrm{Ca}^{2+}$ level was increased by $10 \mathrm{~mm}$ carnosine (Fig. 6). Carnosine did not affect intracellular $\mathrm{Ca}^{2+}$ concentration up to $4 \mathrm{~min}$, and thereafter increased the $\mathrm{Ca}^{2+}$ concentration up to $10 \mathrm{~min}$. Similarly, the carnosine-induced increase in intracellular $\mathrm{Ca}^{2+}$ concentration occurred in the absence of extracellular $\mathrm{Ca}^{2+}$. However, $2 \mathrm{~mm}$ carnosine had no effect on intracellular $\mathrm{Ca}^{2+}$ concentration (data not shown).

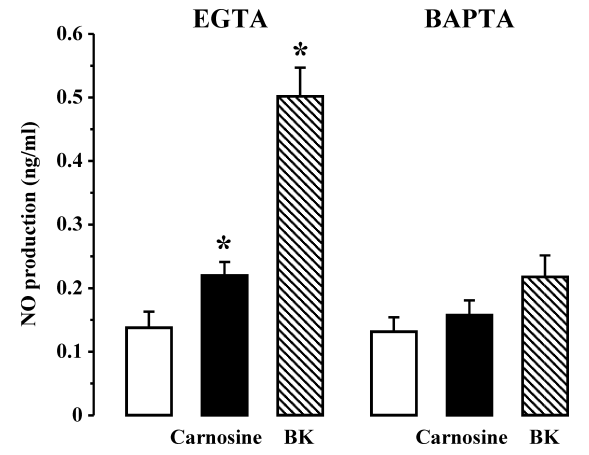

Fig. 5. $\mathrm{Ca}^{2+}$-Dependency of Carnosine-Induced Increase in NO Production in Endothelial Cells

F-2 cells were pretreated with or without $50 \mu \mathrm{M}$ BAPTA-AM in the presence of $1 \mathrm{~mm}$ EGTA, and then stimulated with vehicle (control), $10 \mathrm{~mm}$ carnosine or $1 \mu \mathrm{M}$ bradykinin (BK) for $10 \mathrm{~min}$. The released NO into the medium was determined. The data are mean \pm S.E. for five experiments. $*$ Significantly different from the control.

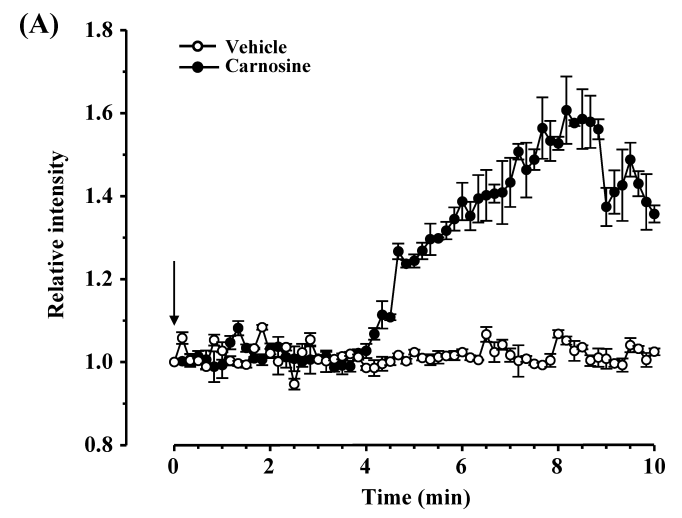

(B)

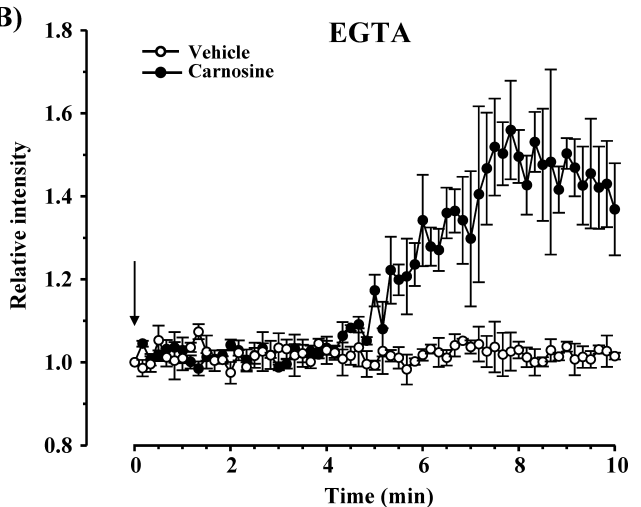

Fig. 6. Effect of Carnosine on Intracellular $\mathrm{Ca}^{2+}$ Concentration in Endothelial Cells

Fluo 3-loaded F-2 cells were preincubated in the absence (A) or presence (B) of $5 \mathrm{~mm}$ EGTA for $5 \mathrm{~min}$, and then stimulated with vehicle or $10 \mathrm{~mm}$ carnosine. Intracellular $\mathrm{Ca}^{2+}$ concentration was continuously measured. Arrows indicate the addition of vehicle or carnosine. The data are mean \pm S.E. for six experiments.

\section{DISCUSSION}

The present studies demonstrate that carnosine facilitates NO production in endothelial F-2 cells. The effect of carnosine was observed only at high concentrations of more than $5 \mathrm{~mm}$. Under normal physiological conditions, it is unlikely that endogenous carnosine regulates endothelial NO production, because the plasma levels of carnosine are low. ${ }^{3}$ However, dietary carnosine might induce an increase in NO pro- 
duction in blood vessels such as the mesenteric and portal veins. The plasma concentration of carnosine is dramatically elevated after ingestion. ${ }^{7)}$ The maximal potency of carnosine to increase NO production was less than $50 \%$ of that of $1 \mu \mathrm{M}$ bradykinin, and its stimulatory effect was observed for about $10 \mathrm{~min}$. These results suggest that dietary carnosine-induced NO production may locally dilate blood vessels, but may not reduce systemic blood pressure. Ririe et al. $^{7)}$ reported that carnosine reduced blood pressure in rats, however, their finding can not be applied to endogenous or dietary carnosine because the decrease was observed in response to a high dose $(33.3 \mathrm{mg} / \mathrm{kg})$ of carnosine administered intravenously. Carnosine causes relaxation in rat aorta ${ }^{7)}$ and constriction of the rabbit saphenous vein, ${ }^{8)}$ implying that the effect of carnosine on endothelial cells may differ between arteries and veins.

The stimulatory effect on NO production in endothelial cells is specific for carnosine. It is reported that the antioxidant ability of carnosine might contribute to its cellular actions. ${ }^{4,6)}$ In addition to carnosine, related compounds such as anserine also exert antioxidative actions. ${ }^{19)}$ In our studies, neither of the constituent amino acids of carnosine ( $\beta$-alanine and/or histidine) nor anserine had an effect on NO production, indicating that the carnosine-induced increase in NO production might be independent of antioxidant action.

It is established that receptor ligands for endothelial cells, such as bradykinin and vascular endothelial growth factor, rapidly increase intracellular $\mathrm{Ca}^{2+}$ levels and cause Akt-mediated phosphorylation of eNOS, resulting in the potentiation of NO production. ${ }^{14,16-18)}$ In contrast, carnosine-induced increases in intracellular $\mathrm{Ca}^{2+}$ levels and NO production were observed after a lag period of $4 \mathrm{~min}$ and $5 \mathrm{~min}$, respectively, and the dipeptide did not induce eNOS phosphorylation. Carnosine concentrations that exceed $5 \mathrm{~mm}$ resulted in $\mathrm{NO}$ production, and these levels were remarkably higher than the effective concentrations of the receptor ligands. Thus, the actions of carnosine quite differ from those of the receptor ligands. Receptors for carnosine have not been found in any cell types. Further investigation is needed for identifying the target protein of carnosine.

Carnosine increased both NO production and intracellular $\mathrm{Ca}^{2+}$ concentration in the absence of extracellular $\mathrm{Ca}^{2+}$. The increased NO production in response to carnosine followed intracellular $\mathrm{Ca}^{2+}$ mobilization, but was abolished by the depletion of intracellular $\mathrm{Ca}^{2+}$. These results indicate that carnosine mobilizes $\mathrm{Ca}^{2+}$ from intracellular $\mathrm{Ca}^{2+}$ stores, leading to $\mathrm{Ca}^{2+}$-dependent eNOS activation. Interestingly, Zaloga et al. ${ }^{20)}$ reported carnosine-induced intracellular $\mathrm{Ca}^{2+}$ mobilization. Carnosine induces $\mathrm{Ca}^{2+}$ release from intracellular stores, thereby increasing intracellular $\mathrm{Ca}^{2+}$ levels in the isolated rat hearts and skinned myocardial fibers.

In conclusion, the present studies demonstrate that carnosine increases NO production in endothelial F-2 cells. The mechanisms of carnosine action on eNOS activation have not been fully clarified, but they may include carnosine-induced $\mathrm{Ca}^{2+}$ mobilization from intracellular stores. The finding of our studies might contribute to the research on the therapeutic applications of carnosine.

Acknowledgments We wish to thank Dr. T. Uchiyama (Kyushu University of Health and Welfare) and Dr. A. Sugiyama (Iwate Medical University) for their assistance.

\section{REFERENCES}

1) Bakardjiev A., Bauer K., Biochemistry (Moscow), 65, 779-782 (2000).

2) Ferraris R. P., Diamond J., Kwan W. W., Am. J. Physiol., 255, G143G150 (1988).

3) Gardner M. L., Illingworth K. M., Kelleher J., Wood D., J. Physiol., 439, 411-422 (1991).

4) Zaloga G. P., Roberts P. R., Nelson T. F., New Horiz., 4, 26-35 (1996).

5) Crush K. G., Comp. Biochem. Physiol. 34, 3-30 (1970).

6) Quinn P. J., Boldyrev A. A., Formazuyk V. E., Mol. Aspects Med., 13, 379-444 (1992).

7) Ririe D. G., Roberts P. R., Shouse M. N., Zaloga G. P., Nutrition, 16, $168-172$ (2000).

8) O’Dowd A., O’Dowd J. J., Miller D. J., J. Physiol., 495, 535-543 (1996).

9) Ignarro L. J., Cirino G., Casini A., Napoli C., J. Cardiovasc. Pharmacol., 34, 879-886 (1999).

10) Hayashi T., Yano K., Matsui-Hirai H., Yokoo H., Hattori Y., Iguchi A., Pharmacol. Ther, 120, 333-339 (2008).

11) Toda K., Tsujioka K., Maruguchi Y., Ishii K., Miyachi Y., Kuribayashi K., Imamura S., Cancer Res., 50, 5526-5530 (1990).

12) Wang Y., Shin W. S., Kawaguchi H., Inukai M., Kato M., Sakamoto A., Uehara Y., Miyamoto M., Shimamoto N., Korenaga R., Ando J., Toyo-oka T., J. Biol. Chem., 271, 5647-5655 (1996).

13) Takahashi S., Uchiyama T., Toda K., Biol. Pharm. Bull., 32, 1840 1843 (2009).

14) Takahashi S., Mendelsohn M. E., J. Biol. Chem., 278, 30821-30827 (2003).

15) Kao J. P. Y., Harootunian A. T., Tsien R. Y., J. Biol. Chem., 264, 8179-8184 (1989).

16) Fulton D., Gratton P. J., McCabe T. J., Fontana J., Fujio Y., Walsh K., Franke T. F., Papopetropoulos A., Sessa W. C., Nature (London), 399, 597-601 (1999).

17) Dimmeler S., Fleming I., Fisslthaler B., Hermann C., Busse R., Zeiher A. M., Nature (London), 399, 601-605 (1999).

18) Gratton P. J., Fontana J., O'Connor D. S., Garcia-Cardena G., McCabe T. J., Sessa W. C., J. Biol. Chem., 275, 22268-22272 (2000).

19) Kohen R., Yamamoto Y., Cundy K. C., Ames B. N., Proc. Natl. Acad. Sci. U.S.A., 85, 3175-3179 (1988).

20) Zaloga G. P., Roberts P. R., Black K. W., Lin M., Zapata-Sudo G., Sudo R. T., Nelson T. E., Am. J. Physiol., 272, H462-H468 (1997). 